\title{
Sweet Orange Fruit Age and Inoculum Concentration Affect the Expression of Citrus Black Spot Symptoms
}

\author{
Guilherme F. Frare, ${ }^{1}$ Geraldo J. Silva-Junior, ${ }^{2}$ Fabrício E. Lanza, ${ }^{2}$ Renato B. Bassanezi, ${ }^{2}$ Thiago G. Ramires, ${ }^{1}$ and Lilian Amorim ${ }^{1, \dagger}$ \\ ${ }^{1}$ Escola Superior de Agricultura “Luiz de Queiroz”, Universidade de São Paulo, 13418-900, Piracicaba, SP, Brazil; and ${ }^{2}$ Fundo de \\ Defesa da Citricultura, 14807-040, Araraquara, SP, Brazil
}

\begin{abstract}
Citrus black spot (CBS), caused by Phyllosticta citricarpa, affects different citrus species worldwide. CBS is mainly expressed as false melanose and hard spot symptoms. There is no consensus in the literature about the period when fruit are susceptible to $P$. citricarpa infection and the length of the CBS incubation period. Therefore, this study aimed to assess the influence of sweet orange variety, fruit age, and inoculum concentration on the incubation period and the expression of different CBS symptoms. Attached fruit of Hamlin, Pera, and Valencia sweet orange at 1.5, 3.0, 5.0, and $7.0 \mathrm{~cm}$ diameter were inoculated with suspensions containing $10^{3}$ and $10^{5}$ conidia $/ \mathrm{ml}$ of $P$. citricarpa. The percent conidial germination was quantified using scanning electron microscopy. The CBS symptoms on fruit were assessed monthly. The four diameters did not significantly affect conidial

germination on the inoculated fruit, although CBS incidences were lower when larger fruit were inoculated. Hard spot symptoms on sweet orange fruit did not develop from the false melanose symptoms and vice versa. The incubation periods for false melanose were shorter than those observed for hard spot. False melanose began to appear 44 days after inoculation, but hard spot only formed at 113 days or later. Incubation periods were shorter and incidences of false melanose were higher following inoculation with higher inoculum concentration and smaller fruit diameter. The incubation period of hard spot varied among varieties and fruit diameters. However, there was no relationship between hard spot incidence and variety. This study provides a better understanding of the factors affecting the variation in the CBS incubation period and disease incidence on fruit.
\end{abstract}

Citrus black spot (CBS), caused by Phyllosticta citricarpa (syn. Guignardia citricarpa), is an economically important disease in tropical and subtropical citrus-growing areas worldwide (EFSA PLH Panel 2014; Kotzé 1981). In mature sweet orange orchards located in regions with highly suitable climates, premature drop of fruit with CBS may reach $80 \%$ (Lanza et al. 2018; Silva Junior et al. 2016a, b). In addition, fruit with high CBS severity are considered unacceptable and are not traded in the fresh market. In the Mediterranean areas of Europe, the presence of the pathogen has been reported in citrus orchards, but CBS symptoms were not observed (Guarnaccia et al. 2017). Furthermore, regulatory measures restrict the importation of fruit from countries with CBS (EFSA PLH Panel 2014; Yonow et al. 2013).

$P$. citricarpa produces both sexual (ascospores) and asexual (conidia) propagules, which have a significant role in CBS epidemics across different regions, such as Brazil and Ghana (Brentu et al. 2012; Reis et al. 2006; Spósito et al. 2011). Conidia are typically produced on dead twigs and in the lesions on leaves and fruit, but ascospores are formed only in leaf litter. Ascospores are dispersed by wind and play an important role in introducing CBS to a citrusgrowing area (Fourie et al. 2013; Spósito et al. 2007). Conidia are washed down over short distance from pycnidium-bearing lesions to nearby susceptible tissues, which means that asexual spores are deposited onto the adjacent fruit, leaves, and twigs. Therefore, conidia increase the CBS intensity in the tree canopy rather than spread the disease over longer distances (Spósito et al. 2011). The P. citricarpa ascospores and conidia are produced during the rainy season when there are frequent alternating dry and wet periods (Kotzé 1981,

${ }^{\dagger}$ Corresponding author: L. Amorim; lilian.amorim@usp.br

Funding: This research was supported by the National Council for Scientific and Technological Development - CNPq (author's scholarships) for financial support.

*The $\boldsymbol{e}$-Xtra logo stands for "electronic extra" and indicates that two supplementary figures are published online.

Accepted for publication 26 October 2018.

C 2019 The American Phytopathological Society
2000). In the citrus-growing areas of Brazil and South Africa, the peaks for ascospore release occur from November through January (Fourie et al. 2013; Reis et al. 2006). The conidia embedded in the cirrus are released from pycnidia usually during rainy seasons (Kotzé 1981, 2000; Spósito et al. 2011). After the deposition of spores on susceptible host tissues, the pathogen starts the infection process and remains quiescent as subcuticular mycelia (Kotzé 1963; McOnie 1967).

At present there is little and variable information concerning the period that the fruit is susceptible to $P$. citricarpa infection and the length of the CBS incubation period, which is considered as the time between infection and symptom expression (Madden et al. 2007). The critical period for infection in South Africa begins at fruit set and lasts for 4 to 5 months (Kotzé 1988). However, in Brazil and Ghana, this period ranges from fruit set to 6 to 7 months later (Baldassari et al. 2009; Brentu et al. 2012; Lanza et al. 2018). It is difficult to determine the incubation period under field conditions because the time of infection is usually unknown. However, periods from 4 to 6 months (Timmer 1999) and more than 6 months (Kotzé 1988) have been reported as being needed for the appearance of CBS symptoms in commercial orchards. A long CBS incubation period may be related to the time when the fruit were infected (Kotzé 1981). Under controlled conditions, the CBS incubation period reported for Valencia sweet orange ranged from 2 to 8 months, and it seemed to be dependent on the fruit development stage at inoculation time. However, it was not affected by inoculum concentration (Aguiar et al. 2012).

Citrus black spot symptoms have been observed on the main commercial citrus species and varieties, such as sweet oranges (Citrus sinensis), lemons (C. limon), mandarins/clementines ( $C$. deliciosa, $C$. reticulata, and $C$. clementina), and some limes $(C$. aurantiifolia and $C$. limettioides), except on Tahiti lime (C. latifolia) (Silva Junior et al. 2016a). Although the symptoms are not reported on Tahiti lime, $P$. citricarpa has been isolated from its asymptomatic tissue (Baldassari et al. 2008). The main sweet orange varieties used in the Brazilian citrus industry are early season Hamlin, midseason Pera, and late-season Valencia (Fundecitrus 2017). These varieties have similar CBS susceptibilities (Spósito et al. 2004). Different types of symptoms may appear on fruit, such as false melanose, hard spot, and freckle spot. False melanose is characterized by small black spots that are commonly observed on green fruit. However, this kind of symptom does not contain 
pycnidia (Kotzé 2000; Silva Junior et al. 2016a). The presence of phenolic compounds around the stomata suggests that the false melanose symptom is a reaction of the host against pathogen infection (Marques et al. 2012). Hard spot, the most typical CBS symptom, appears as light brown to gray lesions surrounded by a dark brown ring. This symptom appears close to the time when the fruit color changes from green to orange. Freckle spot appears as small, red, depressed lesions on ripe fruit and during the postharvest stage. Both hard and freckle spots may have pycnidia in the center of the lesion (Kiely 1948; Kotzé 2000; Spósito et al. 2011). Although it is known that the different CBS symptoms are expressed at different fruit developmental stages, the cause of this variation is unknown. For instance, it has been reported that the false melanose symptom appears a few months after infection when the fruit has supposedly become resistant (Kotzé 1988). Nonetheless, as the symptoms occur on fruit artificially inoculated at different developmental stages (Aguiar et al. 2012), the absence of symptoms on mature fruit inoculated under field conditions may not be related to fruit resistance, but to the long incubation period of the disease.

Determining the period when the fruit is susceptible to P. citricarpa infection may persuade growers to spray fungicides only during the critical period (Lanza et al. 2018). In this study, fruit of Hamlin, Pera, and Valencia at different developmental stages were inoculated with different inoculum concentrations of $P$. citricarpa to elucidate the periods of incubation and susceptibility to CBS.

\section{Materials and Methods}

Inoculation procedure. The $P$. citricarpa isolate was obtained from typical CBS symptoms on Valencia sweet orange fruit and preserved on filter paper at $-20^{\circ} \mathrm{C}$ in the Fund for Citrus Protection (Fundecitrus, Araraquara, Brazil) as described by Silva Junior et al. (2016a). Molecular identification of this isolate was undertaken using species-specific primers for $P$. citricarpa, which were GCP1 and GCP2 (Stringari et al. 2009). The isolate was cultured from the preserved filter paper at $28^{\circ} \mathrm{C}$ for 20 days in petri dishes containing potato dextrose agar (PDA). Inoculum suspensions were prepared by flooding the surface of pathogen cultures with $5 \mathrm{ml}$ of sterile distilled water, scraping the surface, and then filtering the conidia using gauze pad. The $P$. citricarpa conidial concentration was measured with a hemocytometer and diluted to $10^{3}$ and $10^{5}$ conidia $/ \mathrm{ml}$.

The experiment was carried out on 7-year-old Hamlin, Pera, and Valencia sweet orange trees grafted onto Rangpur lime (Citrus limonia). Fifteen trees of each variety were kept in 100-liter pots inside a

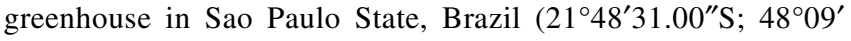
$\left.45.50^{\prime \prime} \mathrm{W}\right)$. The inoculation was performed on 15 attached fruit that were $1.5 \mathrm{~cm}$ in diameter and 10 fruit that were $3.0,5.0$, and $7.0 \mathrm{~cm}$ in diameter for each variety and inoculum concentration. Five fruit from each diameter of all varieties were used as controls. The experiment was performed three times on different dates (Supplementary Fig. S1). The fruit peel color index (CI) was determined at inoculation using a portable Minolta Chroma Meter (Model CR-400, Konica Minolta Sensing Inc., Tokyo, Japan). The fruit peel color readings were expressed as three parameters: differences in green and red $(a)$, blue and yellow $(b)$, and light and darkness $(L)$. The color index was calculated using the following transformation: $\mathrm{CI}=1000 \mathrm{a} / \mathrm{Lb}$
(Jiménez-Cuesta et al. 1981). This transformation results in negative and positive values for the green and orange colors, respectively. A zero value is the midpoint of the color break period. The CI was analyzed by the nonparametric Kruskall-Wallis test at the $5 \%$ probability level.

Inoculations were performed using $2.5 \times 2.5 \times 1.5 \mathrm{~cm}$ (length by width by depth) thick adhesive foam pieces. Holes of 0.5 to $1.0 \mathrm{~cm}$ diameter were made in the middle of the foam, which was waterproofed with colorless nail polish. The foam pieces were affixed with glue on the fruit, and the inoculum suspensions or water (control) were added to the hole. Then the foam surface was covered with adhesive tape for $48 \mathrm{~h}$ to create a humid chamber (Fig. 1). The foam pieces were removed after $48 \mathrm{~h}$ and the inoculation sites marked.

The germination rates for $P$. citricarpa conidia were assessed on the peels of the 1.5, 3.0, 5.0, and $7.0 \mathrm{~cm}$ diameter fruit. Twenty attached fruit (five fruit per diameter) of Pera were inoculated with the $P$. citricarpa suspension containing $10^{5}$ conidia/ml using the method described above with foam pieces. After $48 \mathrm{~h}$ in the humid chamber, a sample with $1 \mathrm{~cm}^{2}$ of peel at the inoculation site from each fruit was removed to quantify the rate of conidia germination using scanning electron microscopy. The samples of fruit peel were fixed in a modified Karnovsky solution (2.5\% glutaraldehyde, $2 \%$ paraformaldehyde in $0.05 \mathrm{M}$ sodium cacodylate buffer, $\mathrm{pH} 7.2$ ) for at least 1 to $2 \mathrm{~h}$ at room temperature and postfixed in a $1 \%$ solution of osmium tetroxide in the same buffer for $1 \mathrm{~h}$. This step was followed by dehydration through a series of graded acetone solutions $(30,50,70$, and $100 \%)$ for 10 min each, dried with a $\mathrm{CO}_{2}$ critical point dryer (Balzers CP040, Balzers, Liechtenstein), mounted on aluminum stubs using double-sided carbon tape, and coated with a 30 to $40 \mathrm{~nm}$ gold film in a metalizer (Balzers MED010, Balzers, Liechtenstein) at $50 \mathrm{~mA}$ for $3 \mathrm{~min}$. The samples were then analyzed using a scanning electron microscope (LEO 435VP, LEO Electron Microscopy Ltd., Cambridge, UK). Germination was defined as the point at which the germ tube length exceeded the spore diameter. Spore germination was assessed in five replicates by counting 100 spores per sample. A replicate was a sample of $0.5 \times 0.5 \mathrm{~cm}$ of peel extracted per fruit.

Disease assessments and data analysis. False melanose and hard spot incidences were determined monthly by visual assessment. Hard and freckle spots were grouped into one category and then collectively referred to as hard spots. The peel color indexes of the fruit were estimated as previously described at the same time that the symptoms were assessed.

The survival function was used to analyze and compare the survival probabilities (\%) and the survival time means (average time to symptom expression) considering each symptom type, the three varieties, four fruit diameters, and two inoculum concentrations. Data of the three experiments were pooled together, as variances were equal, and each fruit was considered a replication. This analysis was performed using SigmaPlot 13.0 (Systat Software Inc., San Jose, CA, USA) by building Kaplan-Meyer curves (nonparametric procedure) and estimating the survival probabilities (Scherm and Ojiambo 2004). The Kaplan-Meyer curves were compared by the log-rank test at the $5 \%$ probability level to test whether the time to CBS symptom
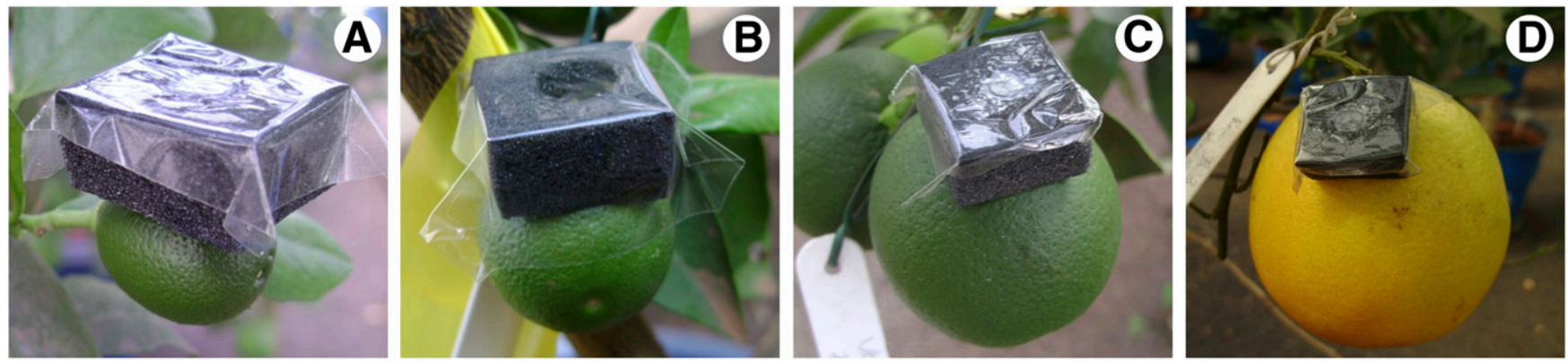

Fig. 1. Phyllosticta citricarpa inoculation on sweet orange fruit that were 1.5 (A), 3.0 (B), 5.0 (C), and 7.0 (D) cm in diameter. Pierced adhesive foams were covered with adhesive tape to create a humid chamber after the conidial suspension was placed inside the waterproofed hole. 
appearance was affected by variety, inoculum concentration, and fruit diameter. When there was a significant difference, the curves were pairwise compared using the Holm-Sidak test at the 5\% probability level. The incubation periods (time required for symptom expression) were compared using 95\% confidence intervals (Copes and Thompson 2008).

The incidences of fruit with false melanose and hard spot in each combination of three sweet orange varieties, two inoculum concentrations, and four fruit diameters were compared using a $3 \times 2 \times 4$ factorial analysis of variance. As incidence is a binary variable, the percentage of diseased fruit in each experiment was considered a replication. When there were significant differences, a Tukey's test at the $5 \%$ probability level was undertaken to compare the means. Data analyses were performed using the R statistical system and the addon package 'ExpDes' (www.r-project.org).

The percentages of germinated conidia for the different fruit diameters were subjected to analysis of variance (ANOVA) using Statistica 13.1 (StatSoft Inc., Tulsa, OK, USA). The means for each treatment were compared using Tukey's test at the 95\% confidence level.

\section{Results}

Conidial germination on fruit. The $P$. citricarpa conidia germination percentage on the fruit surface was about $60 \%$ for all fruit diameters and did not differ among diameters (Fig. 2). In most cases, $P$. citricarpa conidia formed a short germination tube with an appressorium at the end (Fig. 2).

Incidence of fruit with citrus black spot symptoms. There was no significant interaction for diseased fruit percentage among the experiment, variety, inoculum concentration, and fruit diameter factors, irrespective of the type of symptom $(P>0.322)$. Moreover, there was no significant difference $(P>0.482)$ among the experiments. The false melanose symptom was the first CBS symptom observed on the sweet orange fruit of all three inoculated varieties. All lesions did not contain pycnidia (Fig. 3). This symptom appeared as numerous small black spots that are observed in most of green fruit. In some fruit, a yellow halo surrounded the spots at the inoculation site (Fig. $3 \mathrm{~A}, \mathrm{G})$, and in others dark-brown lesions coalesced forming a large lesion covering almost the entire inoculation site (Fig. $3 \mathrm{H}$ ). In most of the fruit inoculated at $5.0 \mathrm{~cm}$ diameter, few lesions were observed at inoculation site (Fig. 3C, F). False melanose incidences were 37, 41 , and $42 \%$ on Hamlin, Pera, and Valencia, respectively, and there were no significant differences between the varieties $(P=0.715$, Fig. $4 \mathrm{~A})$. Incidences of fruit with false melanose were 52 and $28 \%$ for the $10^{5}$ and $10^{3}$ conidia/ml concentrations, respectively $(P<0.001$, Fig. 4B). Fruit diameter had a significant effect on false melanose incidence. The highest incidence of symptomatic fruit (about $80 \%$ ) was observed for fruit inoculated at $1.5 \mathrm{~cm}$ diameter, and this was significantly different from the other fruit sizes. False melanose appeared on 26 and $9 \%$ of the fruit inoculated at 3.0 and $5.0 \mathrm{~cm} \mathrm{di-}$ ameter, respectively, and there was no significant difference in the incidence between these two diameters. The symptoms on fruit inoculated at $5.0 \mathrm{~cm}$ diameter only appeared when the highest inoculum concentration was used. No false melanose symptoms were observed on fruit inoculated at $7.0 \mathrm{~cm}$ diameter, irrespective of variety and inoculum concentration (Fig. 4C).

There were no significant differences in hard spot incidences among the varieties $(P=0.875$, Fig. 4D). However, a higher incidence was observed when $10^{5}$ conidia/ml was used compared with $10^{3}$ conidia/ml $(P=0.004$, Fig. $4 \mathrm{E})$. In contrast to false melanose, hard spot was observed on the inoculated fruit of all diameters (Fig. 4F). Different intensities of hard spot lesions were observed on the inoculated fruit site, regardless of the fruit diameter, variety, or inoculum concentration (Fig. 5). Some fruit had few (Fig. 5B, G, H, K), but others had many (Fig. 5C, D, F, J) hard spot lesions at the inoculated area. Fruit inoculated at $1.5 \mathrm{~cm}$ diameter showed a greater amount of false melanose than hard spot lesions (Fig. 5A,
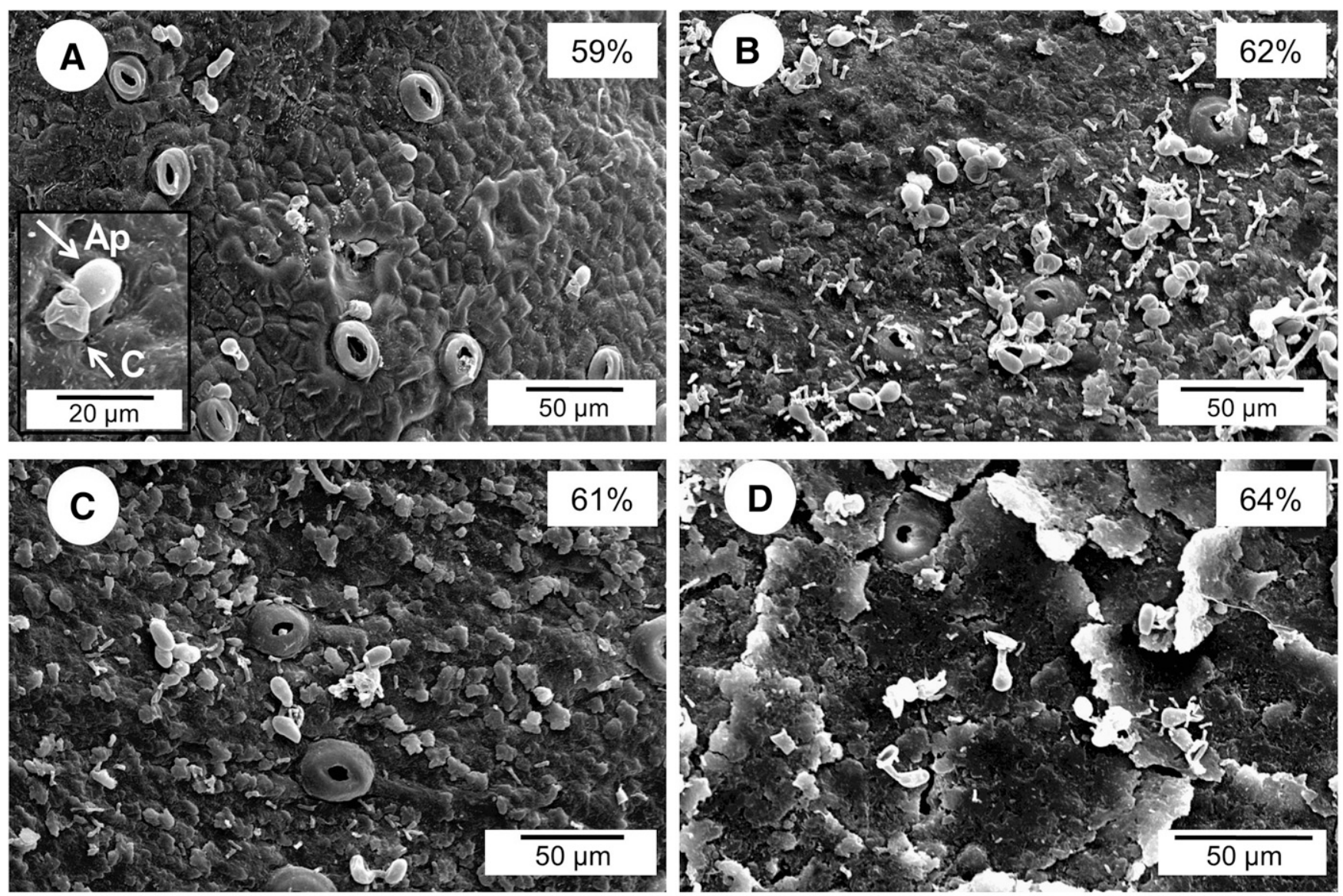

Fig. 2. Electron micrographs of conidial (C) germination and appressorium (Ap) formation on the surface of Pera sweet orange fruit at 1.5 (A), 3.0 (B), 5.0 (C), and 7.0 (D) cm diameter after $48 \mathrm{~h}$ in the humid chamber. 
E, I). Some fruit inoculated at $7.0 \mathrm{~cm}$ diameter had large lesions similar to the virulent spot characterized by dark-brown and depressed lesions formed from the coalescence of hard spot that cover the entire inoculated area (Fig. 5D, L). Pycnidia were observed at the center of the most hard spot lesions on fruit inoculated at $1.5,3.0$, and $5.0 \mathrm{~cm}$ (Fig. 5A, C, G, J), but no reproductive structure of $P$. citricarpa was formed on fruit inoculated at $7.0 \mathrm{~cm}$ diameter (Fig. 5D, H, L). Hard spot incidences ranged from $11 \%(5.0 \mathrm{~cm}$ diameter) to $56 \%(1.5 \mathrm{~cm}$ diameter), and there were significant differences in hard spot incidence between the fruit diameters $(P<0.001$, Fig. 4F).

False melanose appeared earlier in green fruit, and did not develop into hard spots. Hard spots were observed in parts of the inoculated fruit surface without false melanose lesions. Some freckle spots characterized by small red depressed lesions became hard spot. The higher inoculum concentration induced dark-brown spots in large numbers, which coalesced to form extensive cracked areas. (Supplementary Fig. S2).
False melanose incubation period. There was no significant interaction between the evaluated factors. The means of false melanose incubation periods for Hamlin, Pera, and Valencia were 84, 78, and 81 days postinoculation (dpi), respectively, and there were no significant differences among the varieties (Fig. 6A). The first symptomatic fruit was observed at $44 \mathrm{dpi}$, and the longest time it took symptoms to appear was 182 dpi (Fig. 6A). The false melanose incubation period was longer when a lower inoculum concentration was used. Fruit inoculated with $10^{5}$ conidia/ml had an average incubation period of 75 days, which was $15 \%$ shorter than when the $10^{3}$ conidia $/ \mathrm{ml}$ concentration was used for the inoculation (Fig. 6B). The first false melanose symptom appeared at $44 \mathrm{dpi}$ on fruit inoculated with $10^{5}$ conidia/ml, whereas the first symptom on fruit inoculated with $10^{3}$ conidia/ml was detected at $65 \mathrm{dpi}$. It took as long as 170 to 182 dpi for false melanose to appear on some fruit inoculated with either concentration (Fig. 6B). Fruit diameter had a significant effect on the false melanose incubation period. Fruit inoculated at $5.0 \mathrm{~cm}$
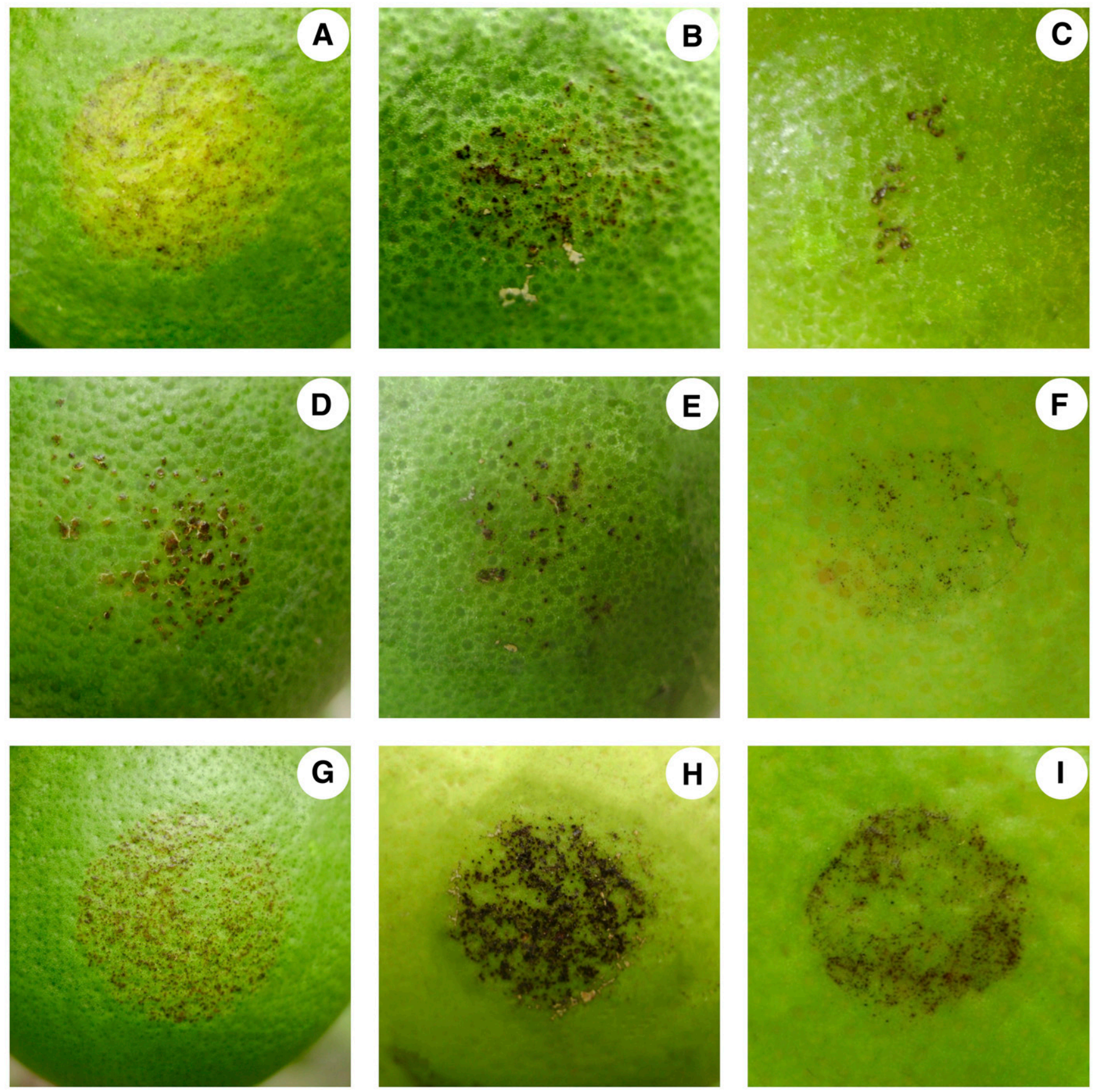

Fig. 3. False melanose symptoms expressed in different intensities as small black spots with or without yellow halo on attached fruit of Hamlin (A-C), Pera (D-F), and Valencia (G-I) sweet orange varieties inoculated with Phyllosticta citricarpa at $10^{5}$ conidia/ml when the fruit were $1.5(A, D, G), 3.0(B, E, H)$, and $5.0(C, F, I) \mathrm{cm}$ in diameter. 
had a mean incubation period of 159 days, whereas fruit inoculated at $3.0 \mathrm{~cm}$ had a mean incubation period of 108 days, both of which were significantly longer than the mean of 68 days observed for fruit inoculated at $1.5 \mathrm{~cm}$ diameter. The ranges for the false melanose expression periods on fruit inoculated at $1.5,3.0$, and $5.0 \mathrm{~cm}$ diameter were 44 to 120, 88 to 170 , and 113 to 182 dpi, respectively (Fig. 6C).

Hard spot incubation period. The average incubation period for the hard spot symptom on fruit was significantly longer for Hamlin (251 days) and Pera (263 days) than for Valencia (192 days) (Fig. 7A). The ranges for symptom expression on Hamlin, Pera, and Valencia were 145 to 360,148 to 365 , and 113 to $297 \mathrm{dpi}$, respectively. Inoculum concentration had no effect on the average incubation period for hard spot. Symptoms appeared from 137 to 330 and 113 to 365 dpi on fruit inoculated with $10^{3}$ and $10^{5}$ conidia/ml, respectively (Fig. 7B). The average incubation period for this symptom ranged from 195 to 253 days for the different fruit diameters (Fig. 7C). Incubation periods observed for fruit inoculated at 1.5 and $3.0 \mathrm{~cm}$ diameter were higher than that observed for fruit inoculated at $5.0 \mathrm{~cm}$, but did not differ from the incubation period observed for fruit inoculated at $7.0 \mathrm{~cm}$ diameter (Fig. 7C). The ranges for hard spot expression on fruit inoculated at $1.5,3.0,5.0$, and $7.0 \mathrm{~cm}$ diameter were 137 to 365,113 to 360,113 to 267 , and 120 to $310 \mathrm{dpi}$, respectively (Fig. 7C).

Citrus peel color index. Fruit inoculated at 1.5 and $3.0 \mathrm{~cm}$ diameter were dark green and had similar color indexes (Table 1). The peel index for the fruit inoculated at $5.0 \mathrm{~cm}$ diameter was higher than the indexes for the smaller fruit, even though all fruit were still green at inoculation time. The fruit inoculated at $7.0 \mathrm{~cm}$ had the highest color index, and the values showed that the fruit were close to the color break stage. The color index at the false melanose expression time was higher for fruit inoculated at $5.0 \mathrm{~cm}$ diameter compared with the fruit inoculated at 1.5 and $3.0 \mathrm{~cm}$ diameter, even though all the fruit were green (Table 1, Fig. 8). On average, the fruit peel color index at the time of hard spot expression was close to color break (color index zero), irrespective of fruit diameter (Table 1, Fig. 8).

\section{Discussion}

This study improves the current understanding about CBS symptom expression. The results show that the expressions of false melanose and hard spot symptoms are independent. Reports about CBS occurrence in the field suggested that a false melanose sometimes develops into a hard spot when the fruit color changes from green to orange (Kotzé 1988, 2000). However, as reported by Marques et al. (2012), our results show that the hard spot symptoms occur later and do not develop from false melanose symptoms. In fact, hard spot symptoms appeared only from a fruit inoculated area without false melanose. Despite this difference, both symptoms have long incubation periods. The durations of these periods may be influenced by the fruit stage at inoculation time and the inoculum concentration. In contrast, the incubation period is not affected by the sweet orange variety maturation time (early-maturing, midseason, or late-maturing). Other studies reported long and variable CBS incubation periods (Aguiar et al. 2012; Baldassari et al. 2009; Brentu et al. 2012; Kotzé 1981). However, none of these studies associated the changes in incubation period with the type of symptom.

False melanose is restricted to the immature fruit, and this type of CBS symptom was first observed on fruit from all three sweet orange varieties. The shortest incubation periods were 44 and 88 days for the fruit inoculated at 1.5 and $3.0 \mathrm{~cm}$ diameter, respectively. At inoculation time, these fruit had a dark green color. No significant change was observed in fruit color in the time between inoculation and false melanose expression. Fruit inoculated at $5.0 \mathrm{~cm}$ diameter were dark green at inoculation time and light green at symptom expression. The incubation periods were always greater than 113 days for the $5.0 \mathrm{~cm}$ fruit. The expression of false melanose symptoms in green sweet orange fruit has also been noted by others (Baldassari et al. 2009; Dewdney et al. 2016; Kotzé 1963, 1981). In contrast, false melanose was not observed on fruit inoculated at $7.0 \mathrm{~cm}$ diameter, which was close to maturation at the color change stage (from green to orange). High concentrations of phenolic compounds, particularly flavonoids, have been found in the green fruit from different citrus species, such as $C$. poonensis, $C$. erythrosa, $C$. tardiferax, C. succosa, $C$. suavissima

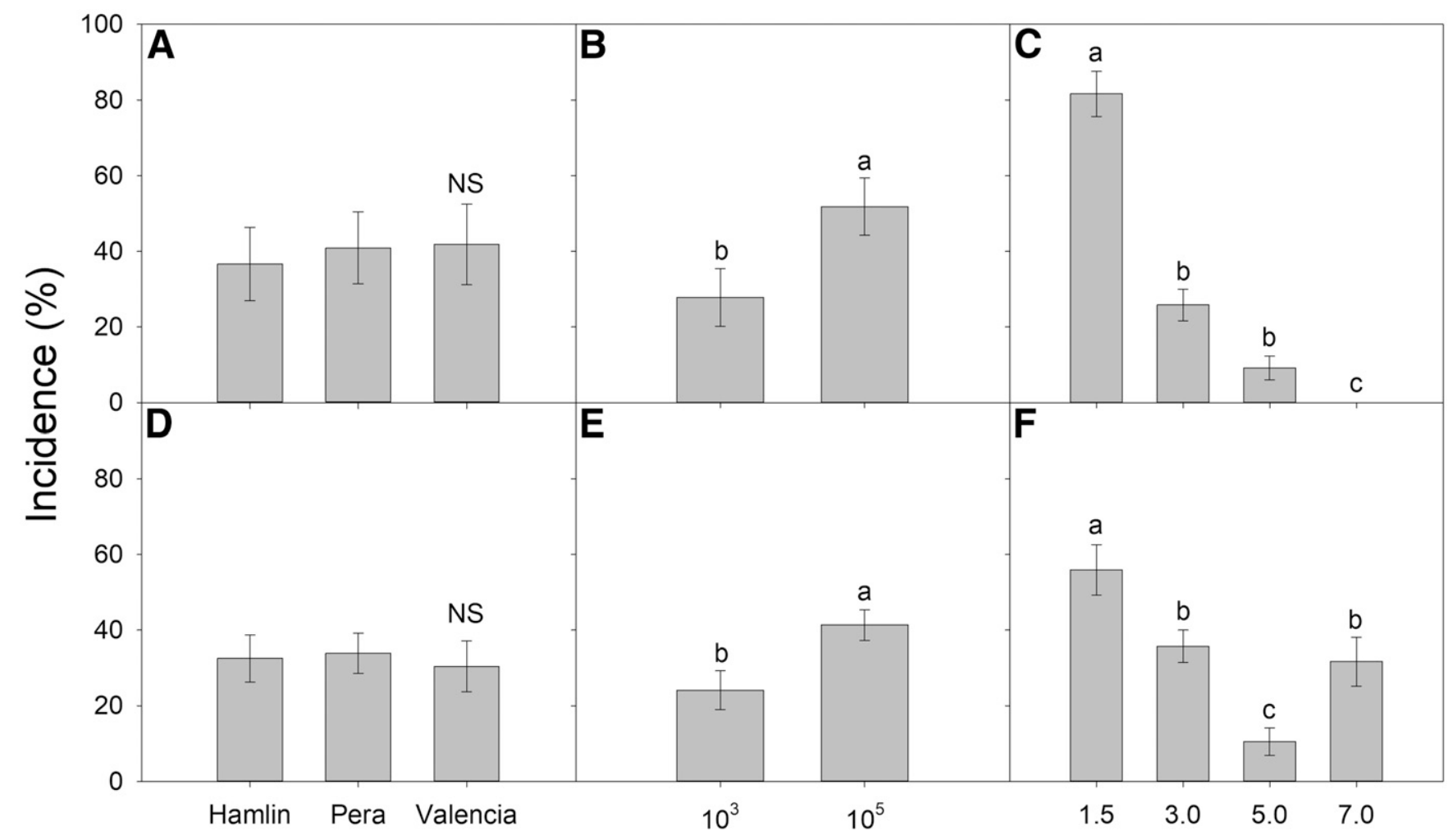

Fig. 4. Incidences of fruit with false melanose (A-C) and hard spot (D-F) symptoms on three sweet orange varieties (A, D); when inoculated with Phyllosticta citricarpa at $10^{3}$ and $10^{5}$ conidia/ml $(B, E)$; when the fruit were $1.5,3.0,5.0$, and $7.0 \mathrm{~cm}$ in diameter $(C, F)$. For each factor, bars in panels in each column that share the same letter are not significantly different from each other according to Tukey's test $(P<0.05)$. NS, not significant. Bars represent the standard error of the mean. 
(Ye et al. 2011), C. unshiu (Moriguchi et al. 2001), and C. aurantium (Castillo et al. 1992). Although some flavonoids may increase or remain stable throughout fruit development (Ortuño et al. 1999), the total contents in most fruits decrease as they ripen (Moriguchi et al. 2001).
The high levels of flavonoids during the first stages of fruit development may be related to pathogen defense (Castillo et al. 1992) and to false melanose expression. At the histological level, false melanose is associated with the presence of phenolic compounds in
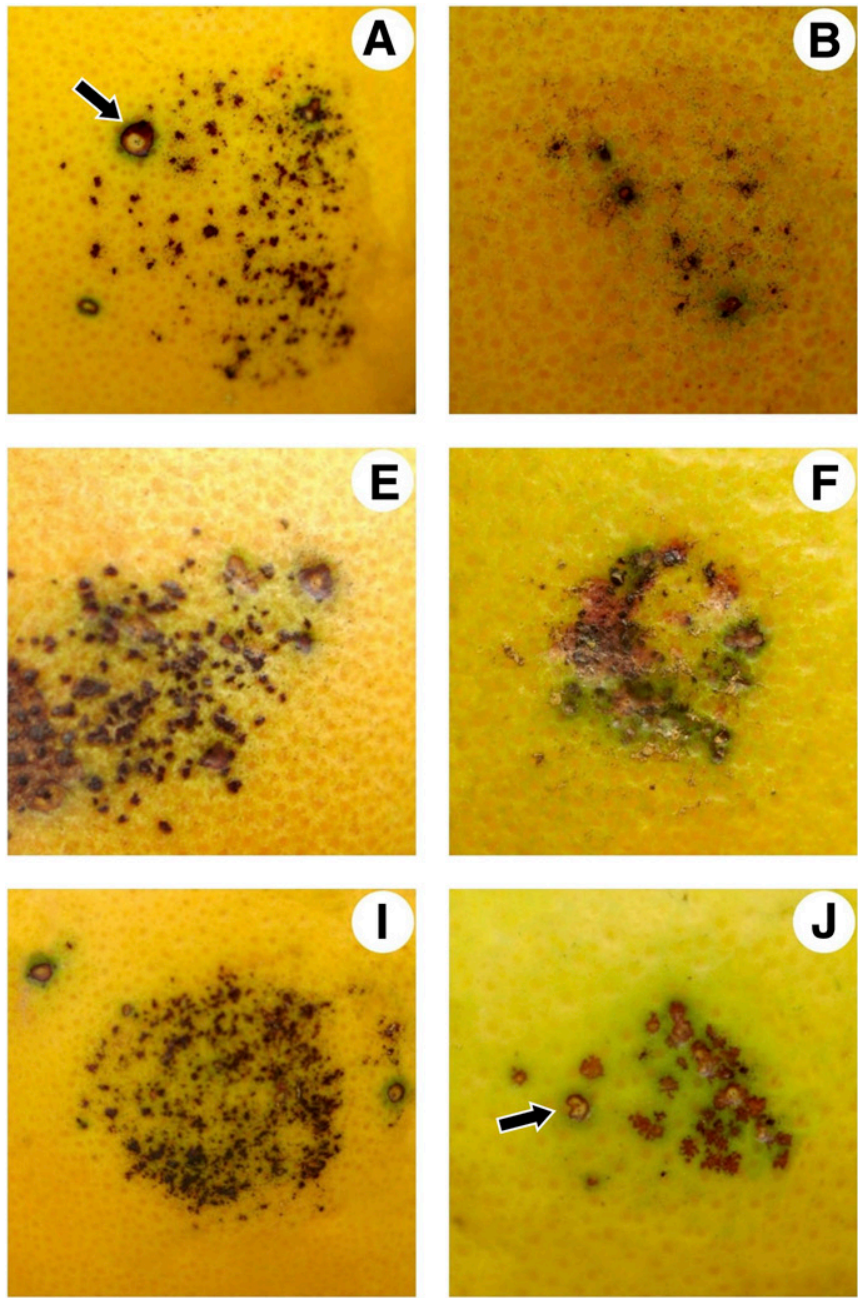
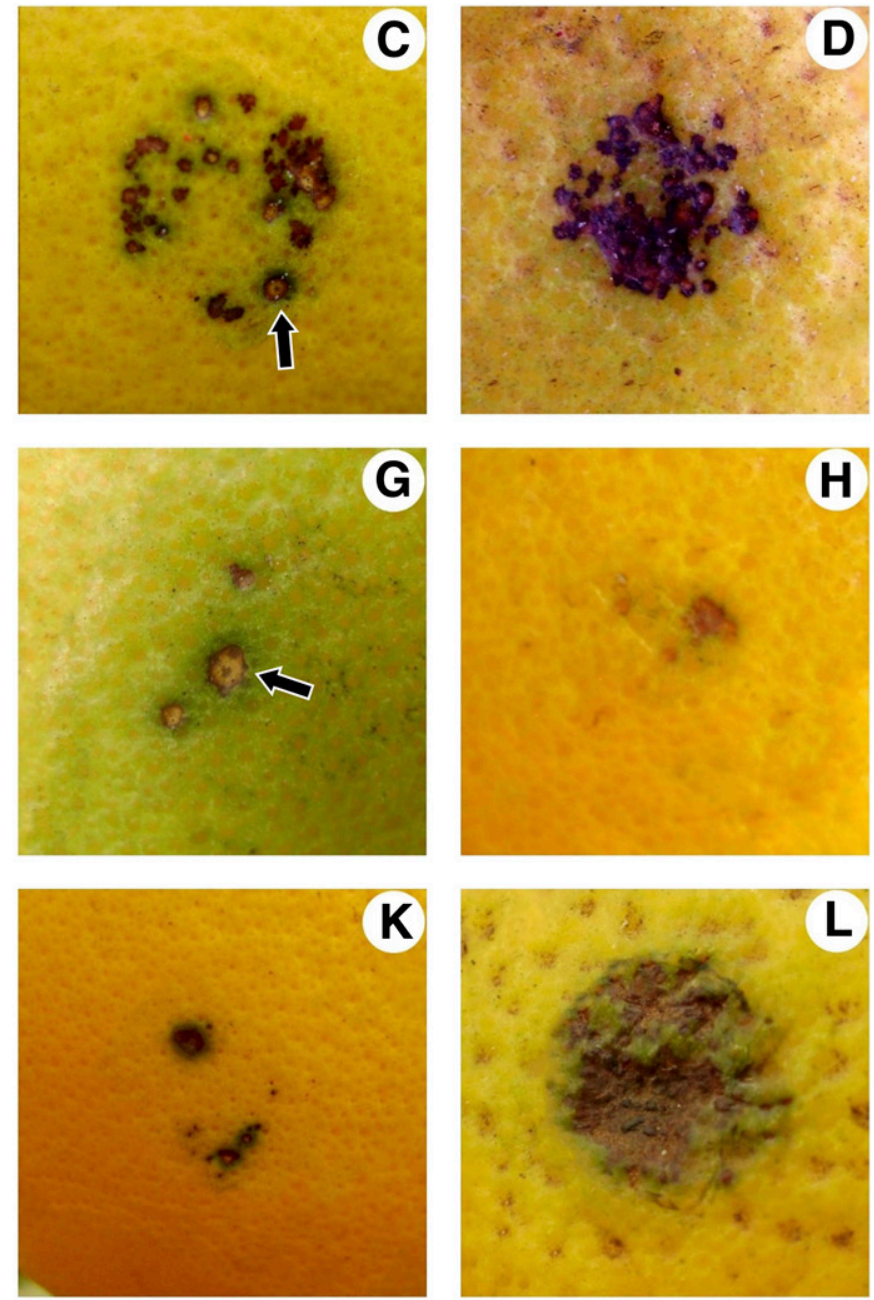

Fig. 5. Hard spot symptoms expressed in different intensities as light brown to gray lesions surrounded by a dark ring on attached fruit of Hamlin (A-D), Pera (E-H), and Valencia (I-L) sweet orange varieties inoculated with Phyllosticta citricarpa at $10^{5}$ conidia/ml when the fruit were $1.5(\mathrm{~A}, \mathrm{E}, \mathrm{I}), 3.0(\mathrm{~B}, \mathrm{~F}, \mathrm{~J}), 5.0(\mathrm{C}, \mathrm{G}, \mathrm{K})$, and $7.0(\mathrm{D}, \mathrm{H}, \mathrm{L}) \mathrm{cm}$ in diameter. Black arrows indicate the hard spot lesions with pycnidia.

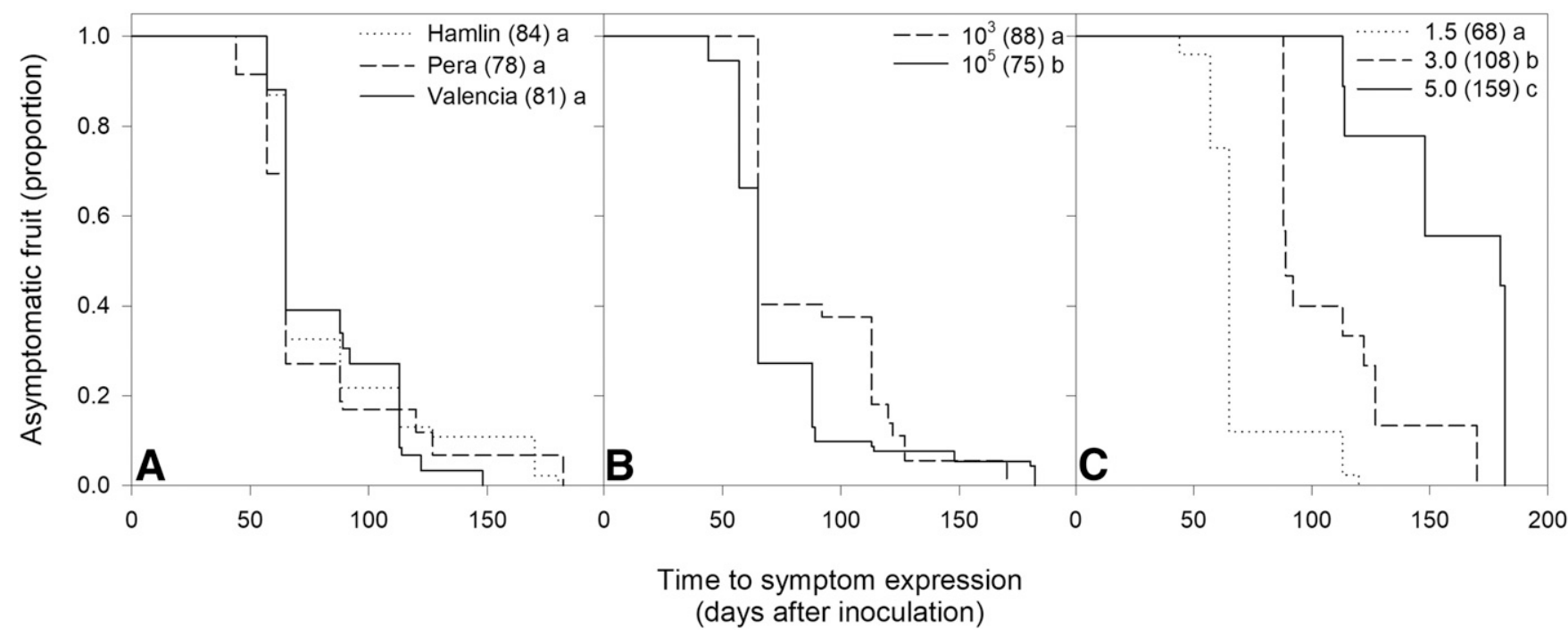

Fig. 6. Kaplan-Meier survival curves for the probabilities that the fruit do not show the false melanose symptom based on variety, inoculum concentration and fruit diameter. (A) Hamlin, Pera, and Valencia sweet orange fruit; (B) inoculum at $10^{3}$ or $10^{5}$ conidia/ml of Phyllosticta citricarpa; (C) fruit diameters of $1.5,3.0$, or $5.0 \mathrm{~cm}$. For each panel, incubation periods expressed as survival times followed by the same letter do not differ significantly according to their confidence interval $(P=0.05)$. 
stomatal guard cells and substomatal chambers (Marques et al. 2012). In addition, a wound meristem, which originates as a small pustule by periclinal divisions, has been observed on the surface of the pericarp (Marques et al. 2012). Both biochemical and structural barriers to pathogen infection are evidence of the host defense reaction (Bostock and Stermer 1989; Nicholson and Hammerschmidt 1992).

In quiescent infections of tropical and subtropical fruit trees caused by Colletotrichum spp. (Prusky 1996; Prusky et al. 1982) and Alternaria spp. (Droby et al. 1986), the pathogen germinates and produces an appressorium, which remains quiescent in green fruit due to host defense reactions. There is no expression of disease symptoms during this quiescent period in many different kinds of unripe fruit. Some reactions similar to those reported for the quiescent diseases of a number of fruit trees may occur in the green fruit of sweet orange inoculated with $P$. citricarpa. As observed for other causal agents of quiescent diseases, $P$. citricarpa remains viable in false melanose lesions, but no reproductive structures are formed (Fig. 3; Silva Junior et al. 2016a). In contrast to other quiescent diseases of fruit trees, the defense reaction against $P$. citricarpa in unripe citrus fruit appears to be visible as a false melanose. The structural changes in the fruit epicarp, which lead to the false melanose symptom, are permanent. Therefore, false melanose lesions do not turn into hard spots.

Hard spot symptoms differ anatomically from symptoms of false melanose. There is no wound meristem, the epidermis is maintained as a coating tissue, there are considerable changes in the epicarp and mesocarp and there are lysed and collapsed cells around the oil glands, there is abundant pathogen colonization in the epicarp cells, and there are one or more pycnidia in the lesions (Marques et al. 2012). Hard spot symptoms appeared from 113 to 360 days after inoculation, and the incubation periods were longer than those observed for false melanose. The hard spot incubation period declined as the fruit aged, and longer periods were observed for fruit inoculated at 1.5 and $3.0 \mathrm{~cm}$ diameter. The long incubation period needed for hard spot expression supports field observations, which also showed that this kind of CBS symptom usually appeared after the fruit color changed from green to orange (Kotzé 1988). The long incubation period may be explained in part by the slow colonization of fruit tissue by the pathogen. In fact, under controlled conditions, $P$. citricarpa needs a long time to grow on artificial media (Baayen et al. 2002).

The Hamlin, Pera, and Valencia varieties had similar incidences of both false melanose and hard spot. These results obtained in the greenhouse corroborate the previous data collected from a field trial conducted in Brazil with the same varieties, which showed similar CBS susceptibility when the disease progress rates were compared (Spósito et al. 2004). High CBS incidences were associated with high concentrations of spores and with fruit being inoculated during the early developmental stages. False melanose and hard spot incidences decreased as the fruit diameter increased from 1.5 to $5.0 \mathrm{~cm}$. When the inoculations were performed close to the color change, there were no false melanose symptoms, but there was an increase in hard spot incidence. The CBS hard spot result is similar to results reported for peach/prune brown rot, caused by a quiescent infection of Monilinia fructicola (Biggs and Northover 1988; Luo and Michailides 2001). However, the lower disease incidences observed in fruit inoculated with $M$. fructicola at intermediate maturation stages were associated with the lower temperatures recorded during these phases.

The similar germination rates observed for $P$. citricarpa conidia at all fruit diameters show that the differences in incubation period and the incidences of CBS appeared not to be related to the inhibition of conidial germination. Guava black spot symptoms (caused by $P$. psidiicola), similar to hard spot of CBS, only occur during the later fruit

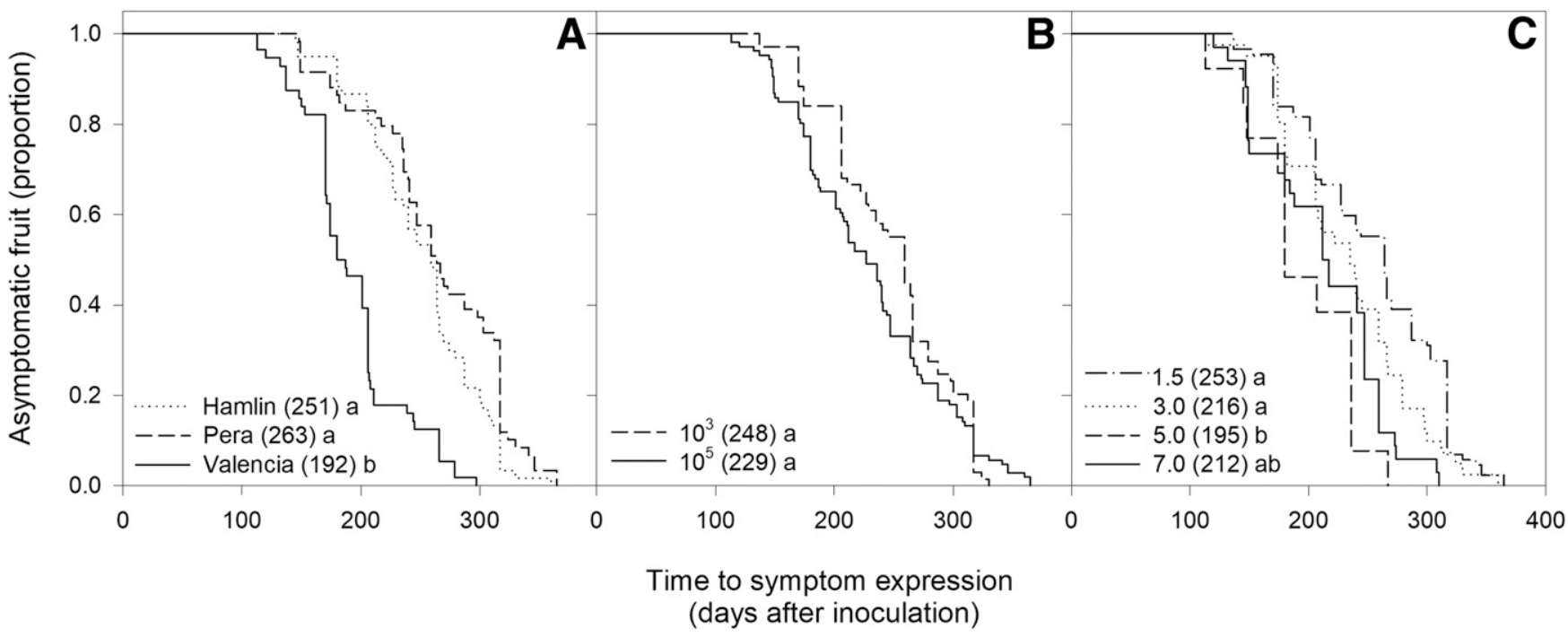

Fig. 7. Kaplan-Meier survival curves for the probabilities that the fruit do not show the hard spot symptom based on variety, inoculum concentration and fruit diameter. (A) Hamlin, Pera, and Valencia sweet orange fruit; (B) inoculum at $10^{3}$ or $10^{5}$ conidia/ml of Phyllosticta citricarpa; (C) fruit diameters of 1.5, 3.0, 5.0 , or $7.0 \mathrm{~cm}$. For each panel, incubation periods expressed as survival times followed by the same letter do not differ significantly according to their confidence interval $(P=0.05)$.

Table 1. Color indexes associated with the expression of false melanose and hard spot symptoms for sweet orange fruit that were inoculated at four different diameters

\begin{tabular}{lccc}
\hline & & Color index $^{\mathbf{z}}$ & \\
\cline { 2 - 4 } Fruit diameter $(\mathbf{c m})$ & Day of inoculation & False melanose expression & Hard spot expression \\
\hline 1.5 & $-17.42 \mathrm{a}$ & $-16.31 \mathrm{a}$ & $-0.78 \mathrm{a}$ \\
3.0 & $-18.24 \mathrm{a}$ & $-15.63 \mathrm{a}$ & $-3.23 \mathrm{~b}$ \\
5.0 & $-15.63 \mathrm{~b}$ & $-6.27 \mathrm{~b}$ & $-3.88 \mathrm{~b}$ \\
7.0 & $-2.52 \mathrm{c}$ & $\mathrm{N} / \mathrm{A}$ & $1.06 \mathrm{a}$ \\
\hline
\end{tabular}

${ }^{\mathrm{z}}$ Means followed by same letter within columns do not differ by nonparametric Kruskall-Wallis test $(P=0.05)$. N/A, not applicable, since false melanose symptom was not observed in fruit inoculated at $7.0 \mathrm{~cm}$ diameter. 


\section{$-20-15-10-5 \quad 0 \quad 5$}

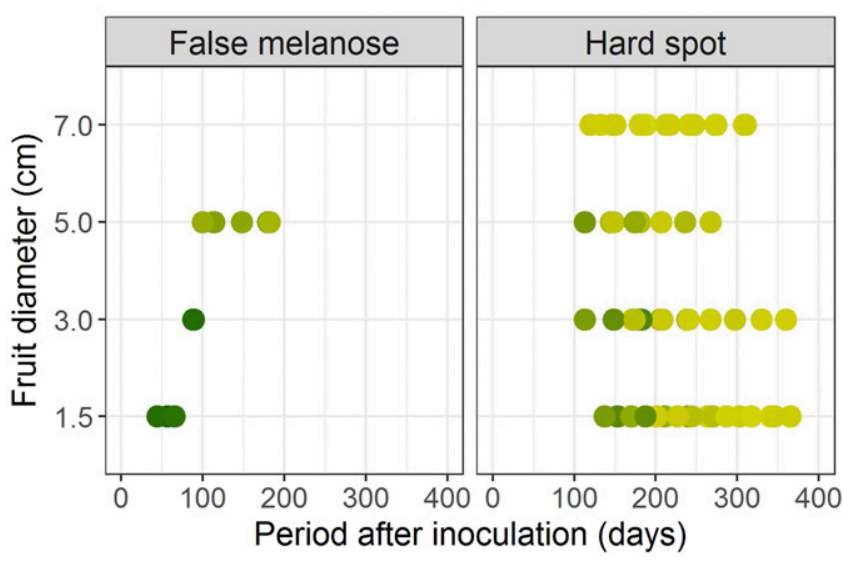

Fig. 8. Color indexes of the fruit and average time for expression of false melanose and hard spot symptoms in fruit based on fruit diameter. Data represent the averages for the three varieties and two inoculum concentrations.

stages. In contrast to our preliminary observation of $P$. citricarpa, conidial germination and appressoria formation by $P$. psidiicola increase as the guava fruit ages (Escanferla et al. 2009).

The CBS spray program starts at the petal fall, which mainly occurs between September and October in the Southern Hemisphere. In South Africa and Australia, fungicide applications for CBS control are not required after January-February. This program is based on reports that sweet orange fruit becomes resistant to infection after the fruit color change (Kiely 1948; Kotzé 1981; McOnie 1964; Miles et al. 2004; Schutte et al. 2012). However, this study demonstrated that the fruit remain susceptible to infection even after the color change when the fruit diameter is about $7.0 \mathrm{~cm}$, regardless of varietal maturation time. Despite the long incubation period, which is around 200 days, the expression of hard spot may occur in late-maturing varieties harvested after October. Therefore, the continuous fruit susceptibility and the highly conducive weather for CBS until April makes it imperative to protect the fruit of late-maturing sweet orange varieties against CBS from October to April in Sao Paulo State, Brazil (Lanza et al. 2018; Silva Junior et al. 2016a, b). However, earlymaturing sweet orange varieties are harvested between June and September, which means sprays with fungicides for CBS control after the color change may be unnecessary because the fruit will have been harvested before most of the hard spot symptoms appear. The behavior observed for $C$. sinensis in this study may not be extrapolated to other citrus species. Similar experiments should be performed with other commercially important cultivars in other citrus growing areas since ontogenic resistance could also explain the lower intensity or absence of CBS symptoms on mature fruit.

\section{Acknowledgments}

We thank J. E. Molina and J. P. Marques for technical support and the NAPMEPA from the University of São Paulo.

\section{Literature Cited}

Aguiar, R. L., Scaloppi, E. M. T., Goes, A., and Spósito, M. B. 2012. Período de incubação de Guignardia citricarpa em diferentes estádios fenológicos de frutos de laranjeira "Valência.". Trop. Plant Pathol. 37:155-158.

Baayen, R. P., Bonants, P. J. M., Verkley, G., Carroll, G. C., van der Aa, H. A., de Weerdt, M., van Brouwershaven, I. R., Schutte, G. C., Maccheroni, W., de Blanco, C. G., and Azevedo, J. L. 2002. Nonpathogenic isolates of the citrus black spot fungus, Guignardia citricarpa, identified as a cosmopolitan endophyte of woody plants, G. mangiferae (Phyllosticta capitalensis). Phytopathology 92:464-477.

Baldassari, R. B., Reis, R. F., and De Goes, A. 2009. A new method for inoculation of fruit with Guignardia citricarpa, the causal agent of citrus black spot. Eur. J. Plant Pathol. 123:1-4.

Baldassari, R. B., Wickert, E., and Goes, A. 2008. Pathogenicity, colony morphology and diversity of isolates of Guignardia citricarpa and G. mangiferae isolated from Citrus spp. Eur. J. Plant Pathol. 120:103-110.
Biggs, A. R., and Northover, J. 1988. Early and late-season susceptibility of peach fruits to Monilinia fructicola. Plant Dis. 72:1070-1074.

Bostock, R. M., and Stermer, B. A. 1989. Perspectives on wound healing in resistance to pathogens. Annu. Rev. Phytopathol. 27:343-371.

Brentu, F. C., Oduro, K. A., Offei, S. K., Odamtten, G. T., Vicent, A., Peres, N. A., and Timmer, L. W. 2012. Crop loss, aetiology, and epidemiology of citrus black spot in Ghana. Eur. J. Plant Pathol. 133:657-670.

Castillo, J., Benavente, O., and Del Río, J. A. 1992. Naringin and neohesperidin levels during development of leaves, flower buds, and fruits of Citrus aurantium. Plant Physiol. 99:67-73.

Copes, W. E., and Thompson, J. L. 2008. Survival analysis to determine the length of the incubation period of Camellia twig blight caused by Colletotrichum gloeosporioides. Plant Dis. 92:1177-1182.

Dewdney, M. M., Schubert, T. S., Estes, M. R., Roberts, P. D., and Peres, N. A. 2016. Citrus Black Spot. 2016 Florida Citrus Pest Manag. Guid. Ch.19. PP279:1-6 Available at: http://edis.ifas.ufl.edu/cg088 [Accessed March 19, 2018].

Droby, S., Prusky, D., Jacoby, B., and Goldman, A. 1986. Presence of antifungal compounds in the peel of mango fruits and their relation to latent infections of Alternaria alternata. Physiol. Mol. Plant Pathol. 29:173-183.

EFSA PLH Panel (EFSA Panel on Plant Health). 2014. Scientific opinion on the risk of Phyllosticta citricarpa (Guignardia citricarpa) for the EU territory with identification and evaluation of risk. Eur. Food Saf. Auth. J. 12: 243.

Escanferla, M. E., Moraes, S. R. G., Salaroli, R. B., and Massola, N. S. 2009. Prepenetration stages of Guignardia psidii in guava: Effects of temperature, wetness duration and fruit age. J. Phytopathol. 157:618-624.

Fourie, P., Schutte, T., Serfontein, S., and Swart, F. 2013. Modeling the effect of temperature and wetness on guignardia pseudothecium maturation and ascospore release in citrus orchards. Phytopathology 103:281-292.

Fundecitrus. 2017. Tree inventory and orange production forecast for the 20172018 season of the São Paulo and west-southwest of Minas Gerais citrus belt Fundo de Defesa da Citricultura. Available at: http://www.fundecitrus.com br/pdf/pes_relatorios/2017_12_05_Tree_Inventory_and_Orange_Production_ Forecast_2017-20181.pdf [Accessed March 19, 2018].

Guarnaccia, V., Groenewald, J. Z., Li, H., Glienke, C., Carstens, E., Hattingh, V., Fourie, P. H., and Crous, P. W. 2017. First report of Phyllosticta citricarpa and description of two new species, $P$. paracapitalensis and $P$. paracitricarpa, from citrus in Europe. Stud. Mycol. 87:161-185.

Jiménez-Cuesta, M., Cuquerella, J., and Martínez-Jávaga, J. M. 1981. Determination of a color index for citrus fruit degreening. Proc. Int. Soc. Citric. 2:750-753.

Kiely, T. B. 1948. Preliminary studies on Guignardia citricarpa spp.: The ascigerous stage of Phoma citricarpa and its relation to black spot of citrus. Proc. Linn. Soc. N.S.W. 73:249-292.

Kotzé, J. M. 1963. Studies on the black spot disease of citrus caused by Guignardia citricarpa Kiely, with particular reference to its epiphytology and control at Letaba. Ph.D. thesis. University of Pretoria, Pretoria, South Africa.

Kotzé, J. M. 1981. Epidemiology and control of citrus black spot in south Africa. Plant Dis. 65:945-950.

Kotzé, J. M. 1988. Black spot. Pages 10-12 in: Compendium of Citrus Diseases. J. O. Whiteside, S. M. Garnsey, and L. W. Timmer, eds. American Phytopathological Society, St. Paul, MN.

Kotzé, J. M. 2000. Black spot. Pages 23-25 in: Compendium of Citrus Diseases. L. W. Timmer, S. M. Garnsey, and J. H. Graham, eds. American Phytopathological Society, St. Paul, MN.

Lanza, F. E., Metzker, T. G., Vinhas, T., Behlau, F., and Silva, G. J., Jr. 2018. Critical fungicide spray period for citrus black spot control in São Paulo state, Brazil. Plant Dis. 102:334-340.

Luo, Y., and Michailides, T. J. 2001. Factors affecting latent infection of prune fruit by Monilinia fructicola. Phytopathology 91:864-872.

Madden, L. V., Hughes, G., and Van den Bosch, F. 2007. The study of plant disease epidemics. APS Press, St Paul, MN.

Marques, J. P. R., Spósito, M. B., Mello, A. F. S., Amorim, L., Mondin, M., and Appezzato-da-Glória, B. 2012. Histopathology of black spot symptoms in sweet oranges. Eur. J. Plant Pathol. 133:439-448.

McOnie, K. C. 1964. Orchard development and discharge of ascospores of Guignardia citricarpa and onset of infection in relation to the control of citrus black spot. Phytopathology 54:1448-1454.

McOnie, K. C. 1967. Germination and infection of citrus by ascospores of Guignardia citricarpa in relation to control of black spot. Phytopathology 57:743-746.

Miles, A. K., Willingham, S. L., and Cooke, A. W. 2004. Field evaluation of strobilurins and a plant activator for the control of citrus black spot. Australas. Plant Pathol. 33:371-378.

Moriguchi, T., Kita, M., Tomono, Y., Endo-Inagaki, T., and Omura, M. 2001. Gene expression in flavonoid biosynthesis: Correlation with flavonoid accumulation in developing citrus fruit. Physiol. Plant. 111:66-74.

Nicholson, R. L., and Hammerschmidt, R. 1992. Phenolic compounds and their role in disease resistance. Annu. Rev. Phytopathol. 30:369-389.

Ortuño, A. M., Arcas, M. C., Benavente-García, O., and Del Río, J. A. 1999. Evolution of polymethoxy flavones during development of tangelo nova fruits. Food Chem. 66:217-220. 
Prusky, D. 1996. Pathogen quiescence in postharvest diseases. Annu. Rev. Phytopathol. 34:413-434.

Prusky, D., Keen, N. T., Sims, J. J., and Midland, S. L. 1982. Possible involvement of an antifungal diene in the latency of Colletotrichum gloeosporioides on unripe avocado fruits. Phytopathology 72:1578-1582.

Reis, R. F., Goes, A., and Timmer, L. W. 2006. Effect of temperature, leaf wetness, and rainfall on the production of Guignardia citricarpa ascospores and on black spot severity on sweet orange. Fitopatol. Bras. 31:29-34.

Scherm, H., and Ojiambo, P. S. 2004. Applications of survival analysis in botanical epidemiology. Phytopathology 94:1022-1026.

Schutte, G. C., Kotze, C., Gideon van Zyl, J., and Fourie, P. H. 2012. Assessment of retention and persistence of copper fungicides on orange fruit and leaves using fluorometry and copper residue analyses. Crop Prot. 42:1-9.

Silva Junior, G. J., Feichtenberger, E., Spósito, M. B., Amorim, L., Bassanezi, R. B., and Goes, A., eds. 2016a. Pinta preta dos citrus: A doença e seu manejo, First. Fundecitrus, Araraquara, São Paulo.

Silva Junior, G. J., Scapin, M. S., Silva, F. P., Silva, A. R. P., Behlau, F., and Ramos, H. H. 2016b. Spray volume and fungicide rates for citrus black spot control based on tree canopy volume. Crop Prot. 85:38-45.

Spósito, M. B., Amorim, L., Bassanezi, R. B., Yamamoto, P. T., Felippe, M. R., and Czermainski, A. B. C. 2011. Relative importance of inoculum sources of
Guignardia citricarpa on the citrus black spot epidemic in Brazil. Crop Prot. 30:1546-1552.

Spósito, M. B., Amorim, L., Ribeiro, P. J., Jr., Bassanezi, R. B., and Krainski, E. T 2007. Spatial pattern of trees affected by black spot in citrus groves in Brazil. Plant Dis. 91:36-40.

Spósito, M. B., Bassanezi, R. B., and Amorim, L. 2004. Resistência à mancha preta dos citros avaliada por curvas de progresso da doença. Fitopatol. Bras. 29: 532-537.

Stringari, D., Glienke, C., Christo, D., Maccheroni, W., and Azevedo, J. L. 2009. High molecular diversity of the fungus Guignardia citricarpa and Guignardia mangiferae and new primers for the diagnosis of the citrus black spot. Braz. Arch. Biol. Technol. 52:1063-1073.

Timmer, L. W. 1999. Disease of fruit and foliage. Pages 107-115 in: Citrus Health Management. L. W. Timmer and L. W. Duncan, eds. American Phytopathological Society, St. Paul, MN

Ye, X.-Q., Chen, J.-C., Liu, D.-H., Jiang, P., Shi, J., Xue, S., Wu, D., Xu, J.-G., and Kakuda, Y. 2011. Identification of bioactive composition and antioxidan activity in young mandarin fruits. Food Chem. 124:1561-1566.

Yonow, T., Hattingh, V., and de Villiers, M. 2013. CLIMEX modelling of the potential global distribution of the citrus black spot disease caused by Guignardia citricarpa and the risk posed to Europe. Crop Prot. 44:18-28. 